\title{
DELEUZE, ESPINOSA E NÓS: ACERCA DO TRATADO DA ETOLOGIA
}

\author{
DELEUZE, ESPINOSA Y NOSOTROS: SOBRE EL TRATADO DE ETOLOGÍA
}

\begin{abstract}
Mateus Verdú ${ }^{1}$
Resumo: O presente ensaio tem como pensamento dominante uma possível leitura da história da filosofia a partir de Deleuze, sobretudo no que concerne aos investimentos interpretativos do filósofo, ao ler Espinosa e sua filosofia de diferenciação da Ética e a moral - tema recorrente na teoria central espinosista que tem como pressuposto a necessidade de um Tratado da Etologia. Operar (n)essa diferença é abrir escuta aos questionamentos, bem como as provocações levantadas por eles e, a partir daí, vislumbrar caminhos na atualidade acerca dos problemas que implicam na questão "que pode o corpo?", sujeito ao poder de ser afetado. Veremos que dirimir esses conceitos é tarefa indispensável frente a posição da elaboração do Tratado da Etologia como o estudo das interações entre velocidade e lentidão dos corpos e a taxonomia da capacidade afetiva de cada sujeito, isto é, a variação dos modos de existência de cada indivíduo relacionada a sua vontade de poder.
\end{abstract}

Palavras-chave: Deleuze; Espinosa; etologia.

Resumen: Este ensayo tiene como pensamiento dominante una posible lectura de la historia de la filosofía de Deleuze, especialmente en lo que se refiere a las inversiones interpretativas del filósofo, leyendo a Espinosa y su filosofía de diferenciación de la Ética y la moral - un tema recurrente en la teoría central de la espinosis que tiene como premisa la necesidad de un Tratado de Etología. Trabajar esta diferencia es abrir la escucha a las preguntas, así como a las provocaciones que éstas plantean y, a partir de ahí, vislumbrar caminos en la actualidad sobre los problemas que implican la pregunta "¿qué puede hacer el cuerpo? Veremos que resolver estos conceptos es una tarea indispensable en vista de la posición de la elaboración del Tratado de Etología como el estudio de las interacciones entre la velocidad y la lentitud de los cuerpos y la taxonomía de la capacidad afectiva de cada sujeto, es decir, la variación de los modos de existencia de cada individuo en relación con su voluntad de poder.

Palabras clave: Deleuze; Espinosa; etología.

Este é um texto-experimento; foi pensado inicialmente para compor contornos ainda conservadores da escrita acadêmica e atualizou-se mediante as questões que nosso tempo e mundo impôs ao sermos um dos epicentros de uma crise viral que ainda varre o planeta. Diante da atualidade que nos atravessa, remodelei-o. Habitei a pausa. Entendi, mais do que nunca, a necessidade da filosofia variar de pontos de vista, hermeticamente fechados e bem elaborados, para pontos de vida, nos quais o que (nos) importa é a necessidade de uma filosofia prática e útil a vida. ${ }^{2}$ Sendo assim, propus, como possibilidade de escrita, algumas variações com vistas a promoção e manutenção da mesma.

\footnotetext{
1 Aluno regular do Programa de Pós-Graduação em Educação pela Universidade Estadual de Campinas (FE/UNICAMP). Membro dos grupos de estudos PHALA e TRANS, desenvolve pesquisa de dissertação de mestrado referente a terminologia "Pedagogia do Conceito", tendo como base a tese de doutorado de Gilles Deleuze, orientada por Maurice de Gandillac e defendida em 1968 pela Sorbonne Université, Différence et répétition. E-mail: mateus.verdu@gmail.com.

${ }^{2}$ Nota escrita ao 03/05/2020 diante de uma crise sanitária que já vitimou, no Brasil, mais de 6 mil pessoas.
} 


\section{Primeira ordem das variações: da prática filosófica como experimentação}

Modo I: Frente à mesa, rodeado por notas aparentemente aleatórias, tête-à-tête com o corpo eletrônico que proverá materialidade aos problemas que neste breve ensaio não se encerram, por instante repentino e diferencialmente repetido de acontecimentos em tempos tão sombrios, das máximas deleuzianas absorvidas entre um provar-nômade aqui, outro ali e ainda acolá, erige-se como território da urgência a atualização necessária da prática filosófica como experimentação de múltiplas variáveis ao infinito. ${ }^{3}$

\section{Segunda ordem das variações: um edifício chamado história da filosofia}

Modo II: Ao longe já se pode escutar os sons dos golpes de martelo, que foram atualizados por Gilles Deleuze ao que é chamado história da filosofia. Uma audição atenta e treinada ao mundopróprio $^{4}$ de uma filosofia da diferença pura e conceitual pode reconhecer esses estridentes efeitos sonoros e olhos bem abertos podem visualizar a desconstrução por completo daquela caquética arquitetura retrógrada como uma espécie de rearranjo interior ${ }^{5}$. Sim! A princípio, cabe aqui dizer, é isso que Deleuze faz ao fazer história da filosofia - um certo exercício de desconstrução do edifício, remodelando-o por dentro e por fora. Conforme suas necessidades, é claro.

A genialidade de Deleuze não se associa apenas ao fato dele ser um grande filósofo, por ter colocado verdadeiros problemas ao seu tempo. Como no caso de sua tese, onde o conceito de diferença passa a ser estudado a partir da própria diferença e não de seus opostos (identidade, semelhança, análogo), alcançando assim uma distinção entre diferença conceitual e conceito da diferença e, posteriormente, um estatuto de diferença pura. $\mathrm{O}$ tom anedótico da previsão de Michel Foucault - afirmando que o século seria deleuziano -, aos distintos autores que se filiaram a esse pensamento, demonstra que a recepção dos seus escritos surtiram efeitos em sua época, evidenciando que as questões tramadas na urdidura do tempo são elaborações que trariam profundas mudanças fermentativas aos modos da filosofia operar. A filosofia nunca seria a mesma depois do efeito Deleuze.

Cabe lembrar que depois de ser coroado como filósofo construtor de suas teorias, mesmo que o alcance delas não fosse estelar (como ele mesmo dizia), observa-se um não abandono por completo dos autores que ele privilegiava. Se investe na perspectiva de que Deleuze tenha consagrado belíssimos trabalhos como filósofo, posteriormente a publicação de sua tese de doutorado, Différence et répétition, mas pouco passou a se interrogar - talvez por já creditarmos nisso um certo tipo de esgotamento - acerca de suas monografias e cursos ministrados na universidade onde lecionou, nos quais o mesmo atribui-se de filósofos outros para fazê-los falarem

\footnotetext{
${ }^{3}$ Exemplo de possibilidade e abertura para a produção filosófica e suas variações. Foi a oitava edição do CONEXÕES DELEUZE que, nas dependências da Faculdade de Educação da Universidade Estadual de Campinas (FE/UNICAMP), em novembro de 2019, promoveu encontros múltiplos de várias áreas e abordagens. Apresento, por ora, e, em tom ensaístico, a parcialidade das reflexões e problemas marginais que venho elaborando ao longo deste intenso processo formativo da atualização de filósofos que muito me dizem.

${ }^{4}$ Cf. UEXKÜLL, Jacob von. Dos animais e dos homens. Trad. Alberto Candeias e Aníbal Garcia Pereira. Lisboa: Editora Livros do Brasil, 1982. Me aproprio do conceito de Uexküll para afirmar que as filosofias também se erguem em consonância com seus interlocutores criando seus mundos-próprios, onde autor-leitor coexistem em dependência. Dos leitores de quaisquer pensamentos, só se pode dizer que passam a entender aquelas proposições por elas fazerem sentidos práticos em suas vidas, como a vespa em sua relação de polinização das flores.

5 Cf. DELEUZE, Gilles. Diferença e Repetição. Trad. Luiz B. L. Orlandi e Guilherme Ivo. Traduzido originalmente de Différence et répétition. Paris: P. U. F., 2018. No prelo. Sugere-se a leitura da introdução da tese de doutorado de Deleuze, sobretudo, a partir da página 39, onde se trata de uma diferença conceitual e uma diferença sem conceito. Com fôlego, o leitor pode ler o primeiro capítulo da tese já referida, onde o autor parece erigir uma espécie de lógica da diferença no interior da história da filosofia.
} 
em função de suas temáticas e questões. Ele passa da história da filosofia à filosofia e esse caminho pode ser mapeado em vários momentos de sua trajetória (estudante, professor da educação básica, professor universitário etc.), mas essa passagem não se dá como abando por completo dos filósofos de sua estante. Dizia ele existir um abismo entre escrever em história da filosofia e filosofar:

Há uma grande diferença entre escrever em história da filosofia e em filosofia. Num caso, estuda-se a flecha ou os instrumentos de um grande pensador, suas presas e seus troféus, os continentes que ele descobriu. No outro caso, talha-se sua própria flecha, ou então arruma-se aquelas que lhe parecem mais bonitas, mas para tentar enviá-las noutras direções, mesmo se a distância transposta é relativamente pequena ao invés de ser estelar (DELEUZE, 2018, no prelo).

Varia-se de um modo (história da filosofia) para outro (filosofia), mas é observável que não elimina a possibilidade da história da filosofia como produtiva. Pelo contrário, o "filósofo da diferença" só afirma existir distinções entre um modo e outro. No primeiro movimento não se está fazendo filosofia, mas se estudando "as flechas", "os instrumentos", com os quais grandes pensadores descobriram ou formularam suas ideias, criando inventivamente. Fica evidenciado uma não hierarquia, estabelecida entre esses modos de produção filosóficos, que são distintos e, bem efetuados, despertam potências inventivas para a vida prática dos sujeitos. Caberia aqui apenas uma única questão: ao se construir um problema filosófico, pela via da história da filosofia, age-se filosoficamente ou apenas se interpreta?

Para Deleuze isso seria um falso problema. Pois a única resposta plausível é se perguntar sobre o que se faz, filosoficamente ou pela via da interpretação, ressoa vitalmente para o sujeito que executa, se exerce sentido prático em sua vida. Se a resposta for em tom sonoramente recíproca e positiva, diria Deleuze que a filosofia cumpre seu papel ao estabelecer a ligação do vivente com uma possibilidade de vida, com uma variação do seu modo de existência. Se o exercício de interpretação de qualquer proposição filosófica passa a fazer sentido para seu leitor é porque não é mais ele (autor) quem apenas fala, mas o interlocutor que o faz falar pelas suas necessidades. É disso que trata Deleuze, quando atualiza Espinosa (corpo) e Uexküll (etologia) no interior de seus problemas.

Entende-se que em Deleuze não há criminalização da história da filosofia, como muitos pensavam ou desejaram fazê-lo falar, em nome de seus interesses e épocas. Seria no mínimo incongruente um filósofo que tanto se dedicou a outros pensamentos afirmar que não se pode atribuir dos outros necessariamente aquilo que não é seu, mas que no exercício criativo de colagem passa também a ser seu. $\mathrm{O}$ filósofo francês não só se atribuiu dos problemas de outros pensadores em seu favor, ele se junta a esses pensamentos e abstrai daí suas necessidades. Ele os enraba de maneira produtiva, rouba criativamente e oferece essa maneira de operar não como "modelo a ser seguido", mas como "possibilidade". Não existem métodos a serem seguidos ou um "manual do usuário" partindo da filosofia da diferença, apenas modos, possibilidades, variações. Daí a recorrente dificuldade em vincular seu modo filosófico a algumas metodologias.

Audacioso e antropófago ${ }^{6}$, passará boa parte da vida atribuindo-se dos amigos e inimigos teóricos. E, mais do que isso, incentivará seus leitores e alunos a incorrerem na mesma prática, desde que os mesmos façam usos inventivos e responsáveis de suas disposições. Da botânica a ciência dos átomos, da medicina aos mapeamentos histórico-geográficos, se esses modos têm algo a dizer a pauta logo torna-se uma prática efetiva e afetiva de escuta ${ }^{7}$.

\footnotetext{
${ }^{6}$ A filosofia de Gilles Deleuze é antropofágica, agindo sempre por incorporações, acoplamentos, atualizações.

${ }^{7}$ Por uma filosofia da escuta: onde se deixam sussurros, gritos, vozes, sons, ruídos e silêncio se manifestarem. Como em John Cage e sua magnífica execução de "4’33 (para nenhum instrumento ou combinação de instrumentos) que se pode ver aqui https://www.youtube.com/watch?v=JTEFKFiXSx4.
} 
Ao ler Espinosa e colocá-lo em seu favor, Deleuze prova-nos que não é o homem da jaqueta furada ${ }^{8}$ que nos fala, mas é ele. Ele não lê seus autores escolhidos fazendo-os falar sobre suas filosofias e temas, ele fala pela boca deles os usando. E é desse potente encontro que Deleuze formula a necessidade da taxonomia de um Tratado da Etologia onde o modelo corpo substitui as perguntas fundadoras da filosofia clássica: de onde viemos? Para onde vamos? Quem somos nós?

Em se tratando de corporeidades, modos, formas, é Espinosa, o príncipe dos filósofos, como sugeriu e escolheu Deleuze, que primeiro propôs uma interpretação potente, tendo o corpo como uma espécie de um novo modelo para a filosofia de sua época, substituindo os falsos problemas do Eu humano elencados acima.

\section{Terceira ordem das variações: Deleuze, Espinosa e nós}

Modo III: A filosofia também se repete e, já que se pôde contar com a repetição de modos filosóficos que nada tem a nos dizer, contar-se-á com modos filosóficos que muito tem a nos dizer ${ }^{9}$. Vez ou outra repetem-se atualizações diferenciais: vê-se um Espinosa surgir no século XVII, um Nietzsche no século XIX e um Deleuze no século $\mathrm{XX}^{10}$. Dos estoicos, passando por Espinosa e Nietzsche - filósofos marginalizados pela filosofia -, até chegarmos em Deleuze, observa-se nestes, ao menos, duas características comuns: (a) são contrários as hegemonias filosóficas de seus tempos e (b) interessam-se por uma filosofia prática que só pode estar em favor de novas possibilidades de vidas. São estas as contra efetuações de seu tempo, pois estão manifestadamente voltados para filosofias vitais. Aliás, só isso lhes interessam no interior de suas filosofias e essa espécie de afinidade eletiva é comum entre eles. Se Deleuze, para seu século, passou a ser considerado um programador que atualiza a história da filosofia, ora lendo-a e se apropriando dela com colagens, fazendo filhos pelas costas, como ele mesmo dizia e, por fim, deletando-a junto ao monopólio filosofal, é por vincular-se apenas a filosofias práticas e úteis a vida.

Para Deleuze filosofia e prática conjugam-se e não podem ser pensadas separadamente uma da outra. Sua obra "Espinosa: Filosofia prática" (DELEUZE, 2002), envolve o leitor pela clareza da argumentação e possibilita uma preciosa sensação de se estar junto a ele que, como um excelente professor, em sala de aula, nunca nos auditórios, deixa a gentil impressão de se estar ombreado com suas questões ali expostas e elaboradas. O bom professor não se enche de soberba por dominar um tema, antes, faz de suas questões problemas para todos - desde que estes queiram tomar para si os problemas, desde que faça sentido incorporá-los. Não há imposição e suas conquistas teóricas são sempre coletivas. Ele é um desses filósofos que parecem dizer muito, mesmo quando não é capturado em sua completude, deixando a sútil sensação de que o filósofo espia seus leitores, aguardando o instante em que seus sopros farão sentido aos sentidos de quem tocou em tais palavras.

Trazendo a importância do filósofo holandês, Espinosa, para o centro da sua filosofia, Deleuze martela uma vez mais o estabelecimento da tradição filosófica e estabelece uma conclusão muito produtiva: não é mais necessário ser filósofo para operar filosoficamente. Daí

\footnotetext{
${ }^{8}$ Conta-se que Espinosa teria sofrido uma tentativa de assassinato, onde o homicida conseguiu esfaqueá-lo não obtendo total sucesso em seu empreendimento. Espinosa andava com a jaqueta furada pelo objeto pontiagudo para se lembrar dos riscos de pensar.

${ }^{9}$ Deleuze não faz escolhas por predileções analíticas ou metodológicas ao preferir Espinosa e Nietzsche ao invés de Descartes, Hume ou Kant. Suas escolhas são pelo fato de que alguns modos filosóficos tem algo a lhe dizer, enquanto outros simplesmente não lhe dizem nada.

${ }^{10}$ Como apresentado no primeiro capítulo de Différence et répétition, e que aqui já citei, a repetição comporta em si uma atualização da diferença.
} 
as próprias manifestações de Kiev sobre Espinosa, ao afirmar que não havia compreendido tudo do que lera, mas que quando conheceu "tais ideias" era como se segurasse "uma vassoura de feiticeira" (DELEUZE, 2002, p. 7).

Se a filosofia de Deleuze orienta seus leitores para exercícios de acoplamento e colagem, pode-se dizer que há aqui, neste ensaio, um duplo e um triplo movimento: ora movimento de interpretação, ora movimento de criação. Do ponto de vista da prudência, a leitura aqui realizada passa pela interpretação de Deleuze acerca de Espinosa e não por Espinosa propriamente dito ${ }^{11}$. Num primeiro momento há um movimento interpretativo sobre a teoria espinosista, no qual Deleuze opera arrancando dali conceitos, fazendo-os agir em favor de sua atualidade, de sua época ${ }^{12}$. Mas ele o faz a partir da criação que é inventiva e originária.

Deleuze, leitor de Espinosa, vale-se de questões suas para fazer seu cúmplice falar. Ele cria, a partir desse potente encontro com o corpus textual espinosista, algo que implica numa classificação geral do poder de afetar e ser afetado de cada corpo. Já se tem "caldo" suficiente para múltiplas interpretações a partir do que Deleuze esboça, mas querer-se-á falar em nome próprio (como sugeriu Deleuze ${ }^{13}$ ) e daí origina-se um movimento de interpretação da interpretação e co-criação; uma soma em pensar junto com Deleuze-Espinosa mas a partir dessa nossa atualidade. Neste sentido, como uma classificação geral do poder dos afetos poderia auxiliar na resolução dos problemas atuais?

Passa-se, como se faz notar, ao movimento triplo da interpretação. Portanto, se trata de uma interpretação da interpretação - algo justo ao se levar em consideração, que Deleuze tenha lido Espinosa satisfatoriamente bem na medida em que o colocou em função de seus problemas. A tarefa aqui passa pela delicada operação de colocá-los, agora, Deleuze e Espinosa, a serviço do tempo atual, reinaugurando e atualizando a potência prática de suas filosofias e a necessidade que a Ética impõe, isto é, operar a partir de uma taxonomia do Tratado da Etologia, que tem por finalidade mapear as relações de velocidade e repouso e o poder de afecção de cada indivíduo, relacionado a sua vontade de poder.

Se a filosofia prática de Espinosa e Deleuze estiver em favor de quaisquer atualidades pode-se ampliar a própria noção de corpo como modo, variação, movimento, agenciador de afetos. Isso significaria dizer que, com Deleuze e Espinosa inaugura-se um território onde suas linhas vulcânicas a todo momento berram: "o que pode o corpo?".

Essa é a grande questão posta por Espinosa e que Deleuze captou-a por dentro. Ele foi absolutamente extemporâneo, intempestivo ao adiantar temáticas que Nietzsche faria virem à tona séculos depois, ou seja, dedicar todo um edifício teórico-filosófico na desconstrução da metafísica platônica e das verdades finais como fundamentações metafísicas de valores morais, deixando claro que o conhecimento jamais pode ser desvinculado da vida. Inaugurase, com Espinosa, a morte de um Deus moral (questão central), e a partir daí um desmonte da filosofia transcendental que minará esta moral e diagnosticará suas implicações que são geradoras de afetos tristes.

\footnotetext{
${ }^{11}$ Não me valho da leitura completa e concisa da "Ética" para tal investimento.

${ }^{12}$ Dispor a filosofia em favor de modos de variação da existência já explicita uma ética interna.

${ }^{13}$ Cf. Deleuze, Gilles. Prefácio à Edição Americana de Diferença e Repetição. "Ter-se-á tentado falar em nome próprio, e se terá aprendido que o nome próprio podia apenas designar o resultado de um trabalho, ou seja, os conceitos que foram descobertos, sob condição de ter sabido fazê-los viver e exprimi-los com todas as possibilidades da linguagem". Trad. de Luiz B. L. Orlandi e Guilherme Ivo. Traduzido originalmente de Différence et répétition. Paris: P.U.F., 2018. No prelo.
} 


\section{Quarta ordem das variações: para não concluir: acerca do tratado da etologia}

A diferenciação da Ética em relação a uma moral é tema recorrente da teoria central espinosista $^{14}$, que tem por efeito a necessidade de um Tratado da Etologia. Operar (n)essa diferença, a partir de Deleuze-Espinosa e Deleuze leitor de Espinosa, é abrir escuta as interrogações levantadas por eles e, a partir daí, clarear caminhos para a atualidade de problemas que implicam na restrição "do que pode o corpo?”, como novo modelo filosófico, frente ao poder de ser afetado. Distinguir esses conceitos é tarefa indispensável frente a posição da inauguração de uma taxonomia das relações de movimento e dos afetos. É disso que se trata a etologia, uma mudança interpretativa a partir do corpo não mais como "forma", mas como uma relação de movimento e repouso que agrupa uma infinidade de potências afetivas.

Para Espinosa existe a necessidade de diferenciação desse par conceitual, Ética e moral, para mapearmos as relações de movimento frente as potências de afeto. Pois "A moral é o julgamento de Deus, o sistema de Julgamento. Mas a Ética desarticula o sistema de julgamentos. A oposição dos valores (Bem/Mal) é substituída pela diferença qualitativa dos modos de existência (bom/mau)" (DELEUZE, 2002, p. 29).

A moral em Espinosa e, nesse sentido, também em Deleuze, é geradora de afetos tristes, pois se relaciona a valores interiores a um sistema de julgamento que tem por finalidade definir o bem e o mal. Deleuze dinamita essa concepção evidenciando a profunda diferença entre estes dois conceitos e, no que tange a moral, aponta uma saída possível pela via da desvalorização de todos os valores. Mera coincidência com Nietzsche não se trata de acaso, pois observa-se também uma possível atribuição fazendo referência ao filósofo alemão.

Ainda, segundo Deleuze, "há, efetivamente, em Espinosa, uma filosofia da "vida": ela consiste precisamente em denunciar tudo o que nos separa da vida, todos esses valores transcendentes que se orientam contra a vida, vinculado às condições e às ilusões da nossa consciência" (DELEUZE, 2002, p. 32).

Isto é, para Deleuze, leitor de Espinosa, a origem da separação do indivíduo da vida é definida pela orientação da moralidade que desde o início esteve contra a afirmação da vida. Por isso a teoria que crítica as paixões tristes estará intrinsecamente ligada a teoria das afecções, pois "um indivíduo é antes de mais nada essência singular, isto é, um grau de potência" (DELEUZE, 2002, p. 33).

O Tratado da Etologia virá na sequência desta distinção entre Ética e moral, pois ele age a partir de duas proposições. Uma primeira diz:

Com efeito, a proposição cinética nos diz que um corpo se define por relações de movimento e de repouso, de lentidão e de velocidade entre partículas. Isto é: ele não se define por uma forma ou por funções. A forma global, a forma específica, as funções orgânicas dependerão das relações de velocidade e de lentidão. Até mesmo o desenvolvimento de uma forma, o fluxo do desenvolvimento de uma forma depende dessas relações, e não o inverso. O importante é conceber a vida, cada individualidade de vida, não como uma forma, ou um desenvolvimento de forma, mas como uma relação complexa entre velocidades diferenciais, entre abrandamento e aceleração de partículas (DELEUZE, 2002, p. 128).

\footnotetext{
${ }^{14}$ Cf. DELEUZE, Gilles. Espinosa: filosofia prática. Tradução Daniel Lins e Fabien Pascal Lins. São Paulo: Escuta, 2002, p. 23. A posição central de Espinosa consiste em afirmar que "[...] há uma única substância que possui uma infinidade de atributos, Deus sive Natura, sendo todas as criaturas apenas modos desses atibutos ou modificações dessa substância.”
} 
Sabe-se que a cinética é um ramo da física moderna que trata da ação das forças nas mudanças de movimento dos corpos. E o que Deleuze faz é mostrar-nos como Espinosa passa a definir os corpos por suas relações de movimento e pelos seus afetos (como será exposto a seguir). Relações de movimento: pois os indivíduos são conjuntos complexos de infinitas e variáveis relações de movimento e repouso, lentidão e velocidade entre partículas. Por isso passa a se entender as vidas não como formas, mas como relações complexas de velocidade (ora rápidas, ora lentas, ora em repouso).

Sobre o afeto como segunda proposição, diz Deleuze:

A segunda proposição referente aos corpos nos remete ao poder de afetar e de ser afetado. Não se define um corpo (ou uma alma) por sua forma, nem por seus órgãos ou funções. E, tão pouco se define um corpo como uma substância ou um sujeito. Cada leitor de Espinosa sabe que os corpos e almas não são para ele nem substâncias nem sujeitos, mas modos. Todavia, se a gente se contentar em pensá-lo teoricamente, não será suficiente. Pois, concretamente, um modo é uma relação complexa de velocidade e de lentidão, no corpo, mas também no pensamento, e é um poder de afetar e de ser afetado, do corpo ou do pensamento (DELEUZE, 2002, p. 128-29).

Nesse ponto a interpretação do corpo como novo modelo para a filosofia faz com que as coisas passem a soar ainda mais interessantes, pois o corpo sempre nos remete ao poder que ele tem de afetar e ser afetado. Ele não é mais definido pelos órgãos, contornos, tamanho ou peso que possui. Sua definição como corpo se dá exclusivamente pela sua relação de movimento e pausa e poder de afetar e ser afetado.

Sua forma pouco importará. Há uma espécie de ampliação gramatical do que se define por corpo; diagnosticado agora por essa dupla proposição: movimento-afeto. Talvez disso tenham resultado os amplos e potentes estudos do filósofo, zoólogo, médico e botânico alemão, Jacob von Uexküll, donde cercado por amplas referências e experimentos fez uma classificação geral do poder de afecção dos animais e dos homens. ${ }^{15}$

Das obras mais importantes, "Dos animais e dos homens" (UEXKÜLL, 1982), o pesquisador desenvolve uma teoria de que os animais e humanos possuem mundos-próprios. Esses mundos próprios só fazem sentidos para cada indivíduo, seja ele homem ou animal, na medida em que a relação com seus meios passa a fazer sentido de preservação da vida: seja este associado a alimentação, segurança de habitação, manutenção da vida e propagação da existência pelo sexo. Ao estudar, por exemplo, o comportamento de morcegos e borboletas, Uexküll constata que os chamados ciclos-de-função dos mundos-próprios destes seres correspondem exclusivamente apenas a sons que tem um sentido interno com sua organização e orientação de seu mundo interior. Baseado em inúmeros experimentos, provou-se que os morcegos e borboletas são surdos para sons que não tem efeitos práticos em suas vidas.

Toda teoria que Uexküll desenvolveu tem por finalidade destruir as concepções mecanicistas, vigentes em sua época, acerca da morfologia dos animais e evidenciar o poder de afetos destes indivíduos. Erige-se, a partir dele, uma espécie de classificação geral dos afetos no mundo animal.

Traçando o próprio exemplo de Deleuze, tomado de empréstimo de Uexküll, o poder de afecção de um carrapato durante toda sua vida estabelece-se como sentido de sua existência apenas três afetos: o afeto luz, pois necessita estar sobre um ramo para cair sobre o mamífero; para despencar sobre o mamífero necessita do afeto olfativo, que desempenha muito bem,

\footnotetext{
${ }^{15}$ Valendo-se de muito colaboradores, Jacob von Uexküll, erige importante estudo ao longo do século XX que dará bases para os empreendimentos posteriores no estudo dos comportamentos dos animais e da própria psicologia animal.
} 
apesar de ser cego e surdo; por fim, o afeto calorífico que permitirá caminhar pelo corpo do hospedeiro até uma região sem pelos, ali instala-se e passa a sugar o sangue de sua vítima que tem temperatura ideal para manutenção de sua vida. Um mundo de três afetos apenas.

Interessante notar que Deleuze arranca de Uexküll sua etologia (espécie de classificação geral dos poderes de afecção animal) para fazê-las agirem no potente encontro com Espinosa. Da etologia observa-se algo como questão: estariam os animais encerrados em seus mundos-próprios? Os homens, por portarem seu logos, poderiam ampliar suas capacidades de afetarem e serem afetados?

Sobre os animais, não humanos, a questão traria um extenso debate e não há tempo suficiente para tratá-la aqui, necessitando de mais investimentos de leitura para comentá-la. No que tange aos homens a questão não é menos fácil e nem menos complicada, mas pode-se arriscar tentativas de possíveis leituras.

A primeira questão a se fazer sobre a ampliação ou não da capacidade afetiva dos homens não passa, necessariamente, pelo aumento ou diminuição da capacidade de se afetarem. Não se trata de quantidade. Trata-se de os homens saberem aquilo que pode afetá-los. E, o terror de Espinosa, é entender que os homens não possuem tal clareza acerca do que são capazes: "eis por que Espinosa lança verdadeiros gritos: Não sabeis do que sois capazes, no bom como no mau, não sabeis antecipadamente o que pode um corpo ou uma alma, num encontro, num agenciamento, numa combinação" (DELEUZE, 2002, p. 130).

Essa é a questão chave posta por Espinosa. Posteriormente, conforme se experimenta, sugere que os homens seriam estes que têm a capacidade molar, de deixarem ser afetados ou isentarem-se dos afetos. Isso importa muito porque, embora os homens não saibam do que são capazes, eles têm o poder de, na medida em que são afetados, escolherem permanecer com aquele tipo de afecção ou isentar-se dela. E para Espinosa só existem dois tipos de afetos: os afetos tristes e os afetos alegres.

O homens, como já dito, portam essa capacidade singular, ainda que restritos ao seu mundo-próprio, de variar, ampliar seu vocabulário afetivo e até inventar novas línguas, mas como não sabem de quais afetos são capazes, Deleuze indica que "nessa longa história de experimentação" ocorra o que ele chama de "demorada prudência", para que se possa construir "planos de imanência ou de consistência" (DELEUZE, 2002, p. 131).

Colocar o Tratado da Etologia, em favor dessa atualidade, significa apenas mostrar que o trabalho inaugurado por Deleuze, colocando o corpo de Espinosa para bailar com a etologia de Uexküll, nunca se encerra. A filosofia de Deleuze traz sempre um ar reticencioso ao texto. Está sempre aberta ao porvir e a novas movimentações desse quebra-cabeça que pode ser disposto de várias formas e ainda sim, no conjunto, sempre trará uma imagem não dogmática da razão, como possibilidade de variação dos modos de existência. Classificar as relações de velocidade dos corpos e seus poderes de afecção não significa montar um quadro fixo e estático. Antes, deixá-lo aberto, pois os afetos variam de corpo para corpo. Vale lembrar do caso do pato, contado por Uexküll, que dizia que um pato que por anos vivera entre humanos e até fora tratado afetivamente como um, não aceitou ficar com seus pares quando foi devolvido ao terreiro e agia como se não conhecesse os outros de sua mesma espécie

\section{Referências}

DELEUZE, Gilles. Espinosa: filosofia prática. Trad. Daniel Lins e Fabien Pascal Lins. São Paulo: Escuta, 2002.

DELEUZE, Gilles. Prefácio à edição americana de Diferença e Repetição. Trad. Luiz B. L. Orlandi e Guilherme Ivo. Paris: P.U.F., 2018. No prelo. 
CAGE, John. 4’33 (para nenhum instrumento ou combinação de instrumentos). Disponível em: https://www.youtube.com/watch?v=JTEFKFiXSx4. Acesso em: 03 mai. 2020.

UEXKÜLL, Jacob von. Dos animais e dos homens. Trad. Alberto Candeias e Aníbal Garcia Pereira. Lisboa: Editora Livros do Brasil, 1982. 